\title{
Identification of a new antimicrobial lysine-rich cyclolipopeptide family from Xenorhabdus nematophila
}

\begin{abstract}
Maxime Gualtieri ${ }^{1,2,3}$, André Aumelas ${ }^{4}$ and Jacques-Olivier Thaler ${ }^{5}$
Entomopathogenic bacteria of the genus Xenorhabdus are known to be symbiotically associated with soil dwelling nematodes of the Steinernematidae family. These bacteria are transported by their nematode hosts into the hemocoel of the insect larvae, where they proliferate and produce insecticidal proteins, inhibitors of the insect immune system and antimicrobial molecules. In this study, we describe the discovery of a new family (PAX) of five antimicrobial compounds produced by fermentation of the Xenorhabdus nematophila F1 strain and purified by cation exchange chromatography and reversed phase chromatography. The chemical structure of PAX 3, a lysine-rich cyclolipopetide, was obtained from the analysis of homo and heteronuclear 2D NMR and confirmed by MS-MS experiments. The five members of the PAX family showed significant activity against plants and human fungal pathogens and moderate activity against few bacteria and yeast. No cytotoxicity was observed on CHO or insect cells. The Journal of Antibiotics (2009) 62, 295-302; doi:10.1038/ja.2009.31; published online 17 April 2009
\end{abstract}

Keywords: antimicrobial; cyclolipopetide; Xenorhabdus

\section{INTRODUCTION}

Gram-negative bacterial strains of the genus Xenorhabdus are known to be symbiotically associated with soil dwelling nematodes of the Steinernematidae family. ${ }^{1-3}$ After entering the insect larvae through natural openings, nematodes release bacteria from their intestine to the host's hemocoel. ${ }^{4}$ Bacteria are involved in killing the insect host by producing insecticidal protein $s^{5}$ and inhibitors of the insect immune system. ${ }^{6-8}$ The bacteria proliferate in the killed host and favor the reproduction of the nematode by degrading the insect biomass ${ }^{9}$ and by producing antibiotics that inhibits the development of the other microorganisms present in the insects corpse (bacteria, fungi) ${ }^{10}$ Boemare et al. ${ }^{11}$ classified the antibiotic activities of Xenorhabdus into two categories: (i) antimicrobial molecules with broad spectrum and (ii) bacteriocins with very narrow spectrum and active only against bacteria closely related to $X$. nematophila. Only a few families of antimicrobial compounds have been described from Xenorhabdus in the literature: xenocoumacins, ${ }^{12}$ xenorhabdins, ${ }^{13}$ indole derivatives, ${ }^{14,15}$ puromycin, ${ }^{16}$ benzylidenacetone, ${ }^{17}$ proteinaceous bacteriocins, ${ }^{11,18}$ and xenortide and xenematide. ${ }^{19}$ All Xenorhabdus strains spontaneously produce two distinct physiological states in vitro, ${ }^{20}$ phase I and II variants. ${ }^{21}$ Phase I variants produce several antibiotics and secrete a variety of proteins, whereas these properties are apparently absent or greatly reduced in phase II variants.
In our screening program, we found new cyclolipopeptidic antimicrobial compounds in the culture supernatant of the X. nematophila F1/1. These compounds possess significant activity against fungi and moderate activity against few Gram-negative and Gram-positive bacteria.

Nonribosomaly antimicrobial lipopetides are produced in bacteria and fungi during cultivation. ${ }^{22-24}$ They are composed of a cationic or an anionic peptide covalently bound to a specifically modified aliphatic chain. Most of the peptidic moieties have complex cyclic structures. Some of these molecules are highly active against bacteria including multiresistant strains. ${ }^{25-28}$ Others display solely antifungal activity $^{22,29}$ and a few both antifungal and antimicrobial activities. ${ }^{22}$ Members of this family were approved for clinical use by the Food and Drug Administration: daptomycine, polymixine, echinochandine. ${ }^{30,31}$

This article describes the fermentation of the X. nematophila F1/1 strain, the isolation and biological activities of these active compounds named PAX (for peptide antimicrobial from Xenorhabdus), and the chemical structure elucidation of PAX 3. This is the first example of lysine-rich cyclolipopetide characterized from the genus Xenorhabdus.

\section{RESULTS AND DISCUSSION}

Fermentation

Xenorhabdus nematophila $\mathrm{F} 1 / 1$ was cultivated for $48 \mathrm{~h}$, at $28^{\circ} \mathrm{C}$ with shaking in a 51 Erlenmeyer flask containing 11 of LB broth. The

\footnotetext{
${ }^{1}$ Selectbiotics, Nîmes, France; ²Université Montpellier 1, Centre d'études d'agents Pathogènes et Biotechnologies pour la Santé, CNRS, UMR 5236, CPBS, 4 Bd Henri IV, CS 69033, Montpellier, France; ${ }^{3}$ Université Montpellier 2, Centre d'études d'agents Pathogènes et Biotechnologies pour la Santé, Montpellier, France; ${ }^{4}$ CNRS UMR5048, INSERM, U554, Centre de Biochimie Structurale, Université Montpellier 1 et 2, 29 rue de Navacelles, Montpellier, Cedex 9, France and ${ }^{5}$ Ecologie Microbienne des Insectes et Interactions Hôtes-Pathogène, UMR 1133, INRA UMII, Montpellier, France

Correspondence: Dr M Gualtieri, Centre d'études d'agents Pathogènes et Biotechnologies pour la Santé, CNRS, UMR 5236, Faculté de pharmacie, Avenue Charles Flahault, Montpellier 34093, France.

E-mail: maxime.gualtieri@univ-montp1.fr
}

Received 6 November 2008; accepted 18 March 2009; published online 17 April 2009 
culture was inoculated with $0.1 \%(\mathrm{v} / \mathrm{v})$ of a $24 \mathrm{~h}$ preculture in the same medium. The antibiotic production was controlled and quantified by diffusion test agar against Micrococcus luteus, and by analytical HPLC.

\section{Isolation}

Bacterial cells were removed by low-speed centrifugation $(6000 \mathrm{~g}$, $10 \mathrm{~min}$ at $4{ }^{\circ} \mathrm{C}$ ) and supernatant was sterilized on $0.22 \mu \mathrm{m}$ pore size filter. Supernatant was added $(1: 1 ; \mathrm{v} / \mathrm{v})$ to a $0.1 \mathrm{M} \mathrm{NaCl}, 0.02 \mathrm{M}$ Tris buffer ( $\mathrm{pH}$ 9) and subjected to cation-exchange chromatography on a Sep Pack CarboxyMethyl cartridge (Acell Plus CM, Waters, Milford, MA, USA). Unbound material was removed by washes with a $0.1 \mathrm{M}$ $\mathrm{NaCl}, 0.02 \mathrm{M}$ Tris buffer ( $\mathrm{pH}$ 9) and the antibiotic eluted with $0.5 \mathrm{M}$ $\mathrm{NaCl}, 0.02 \mathrm{M}$ Tris buffer ( $\mathrm{pH}$ 9). This eluate was acidified with $0.1 \%$ (v/v) trifluoroacetic acid (TFA) and was then subjected to reversedphase chromatography on a Sep Pack C18 cartridge (Sep-Pak Plus $\mathrm{C} 18$, Waters). Unbound material was removed by washing with $\mathrm{H}_{2} \mathrm{O}$ TFA $0.1 \%$, and the antibiotic pool was eluted with acetonitrile. The eluate was concentrated by evaporation under reduced pressure and diluted in water $(1: 5 ; \mathrm{v} / \mathrm{v})$. Pure compounds were isolated from the crude extract by reverse-phase HPLC using a semi-preparative C18 column (Waters; Symmetry Prep C18; $7 \mu \mathrm{m} ; 7.8 \times 300 \mathrm{~mm}$ ), a linear gradient of $\mathrm{H}_{2} \mathrm{O}, 0.1 \%$ TFA-acetonitrile, $0.1 \%$ TFA starting from 20 to $80 \%$ in $30 \mathrm{~min}$, a flow rate of $5 \mathrm{ml} \mathrm{min}^{-1}$ and an UV detection at $214 \mathrm{~nm}$, yielding pure PAX compounds with the following HPLCretention times: PAX $1=19.9 \mathrm{~min}$, PAX $2=20.94 \mathrm{~min}$, PAX $3=21.1 \mathrm{~min}, \mathrm{PAX} 4=21.3 \mathrm{~min}$ and PAX $5=22.3 \mathrm{~min}$ with roughly the $30 / 10 / 50 / 9 / 1$ percentages. The collected fractions were freeze-dried.

\section{Biological properties}

The PAX compounds show antifungal and antibacterial activities. They were tested for antimicrobial activity against a wide range of bacteria and fungi involved in nosocomial infection and phytopathologies (Tables 1 and 2). Regarding human pathogens (Table 1), PAX 1 and 2 did not show antibacterial activity except against Staphylococcus epidermidis and M. luteus. PAX 3 and 4 have weak activity against only few Gram-negative bacteria (Pseudomonas aeruginosa, Escherichia coli and Salmonella typhimurium), moderate activity against $S$. epidermidis and B. cereus and high activity against $M$. luteus. PAX 5 has moderate activity against few Gram-negative (E. coli, P. aeruginosa and S. typhimurium) including multiresistant strains and against few Gram-positive bacteria. However, high activity against the fungus Fusarium oxysporum was observed for PAX 1-5, whereas weak activity was observed against Candida albicans. The fungi belonging to the genus Fusarium are well-known plant pathogens and food contaminants that also cause superficial and subcutaneous infections in humans, such as onychomycosis and keratomycosis. ${ }^{32}$ They have recently emerged as major opportunistic agents in immunocompromised hosts, especially in patients with hemopathy. ${ }^{33,34}$ They are now considered as the third most common fungal genus (after Candida and Aspergillus) isolated from systemic infections in bone marrow transplantation patients. ${ }^{35}$ F. oxysporum is responsible for about $30 \%$ of the human infection caused by this genus. ${ }^{36}$ Regarding phytopathogenic fungi (Table 2), only PAX 1-3 were tested. At 10, 20 and $40 \mu \mathrm{g} \mathrm{ml}^{-1}$, PAX 1 and 3 have strong activity against majority of fungi except Botrytis cinerea myc and Piricularia oryzae sp. PAX 2 has similar activity as PAX 1 and 3 against Cladosporium sp., F. culmorum sp. and Phytophthora. Nevertheless, at 10 and $20 \mu \mathrm{g} \mathrm{ml}^{-1}$, this molecule was less active against other fungi.

No cytotoxic activity with doses up to $1 \mathrm{mg} \mathrm{ml}^{-1}$ against $\mathrm{CHO}$ cells was measured. Injections of the five PAX into the hemocoels of different species of insects did not result in increased mortality. Moreover, these molecules did not exhibit cytolytic activities against sheep erythrocytes or insect hemocytes. These results show that the PAX had no entomotoxic effects (data not shown).

\section{Chemical structure elucidation of PAXs}

Five compounds referred as PAX 1-5 were isolated, purified to homogeneity as a white powder and characterized by mass spectrometry. ESI-MS experiments revealed the molecular weights of different PAXs (PAX 1: $1051 \mathrm{Da}$, PAX 2: $1079 \mathrm{Da}$, PAX 3: $1065 \mathrm{Da}$, PAX 4: $1093 \mathrm{Da})$. PAXs are soluble in water and alcohols and show an UV $\lambda \max$ of $214 \mathrm{~nm}$ (methanol).

\section{Structure elucidation of PAX 3}

The acid hydrolysate of PAX 3 yielded seven amino acids, one glycine (Gly) and six lysine (Lys). Its NMR analysis carried out by homo and hetero nuclear experiments is described below.

The NMR data of PAX 3 (1065 Da) were recorded in DMSO-d6 (Table 3). Its 1D spectrum showed eight amide signals spanning the 8.5-7.3 p.p.m. chemical shift area. Among them, one is a triplet (8.18 p.p.m., 5.7 and $5.7 \mathrm{~Hz}$ ) thus suggesting the presence of a glycine and another displays an unusual doublet of doublet (7.36 p.p.m., 6.5 and $4.0 \mathrm{~Hz}$ ) indicating that this amide group is bound with a methylene group. The six other amide signals are doublets with a ${ }^{3} \mathrm{~J}_{\mathrm{HN}-\mathrm{CH}}$ coupling constant ranging from 5.2 to $7.1 \mathrm{~Hz}$. The natural abundance ${ }^{1} \mathrm{H}-{ }^{15} \mathrm{~N}$ HSQC confirmed the presence of these eight amide protons and the absence of a C-terminal amide group (data not shown). In agreement with the acid hydrolysis, the TOCSY experiment allowed us to unambiguously identify a glycine and six lysine residues (Figure 1a). These later being also characterized from the intense signal at 2.74 p.p.m. typical of the $\mathrm{C}_{\varepsilon} \mathrm{H}_{2}$ protons. Surprisingly, the two-amide signals at 8.38 (doublet) and at 7.36 p.p.m. (doublet of doublet) were found to share the same spin system indicating that the $\zeta$ amino group of this lysine was involved in an amide bond to be identified. From the analysis of the DQF-COSY, TOCSY and NOESY data the assignment of the peptidic part was established on the basis of the classical sequential NOEs and is reported in Figure 1. The peptidic sequence was shown to consist of seven residues as following: $G^{1} K^{2} K^{3} K^{4} K^{5} K^{6} K^{7}$. Unexpectedly, this lysine-rich peptide includes an unusual 5-lysine macrocycle closed by an amide bond between the $\mathrm{K}^{7}$ carboxyl group and the $\zeta \mathrm{K}^{3}$ amino group. Such a cyclization which gives rise to a 5-residue macrolactame ring was mainly supported by the strong intensity dNN NOE between the $\mathrm{K}^{7}$ and the $\zeta \mathrm{K}^{3}$ amide protons and by the successive dNN NOEs observed all around the cycle. Owing to the overlap of the $\mathrm{K}^{6}$ and $\mathrm{K}^{7}$ amide signals, the $\mathrm{dNN}_{6-7} \mathrm{NOE}$ could not be observed in pure DMSO-d6. The addition of $17 \%$ water was enough to separate these two resonances and observe this essential NOE to confirm the cyclic structure giving rise to a 5-residue macrolactame ring. As a result, this cyclization constrains the $\mathrm{K}^{3}$ side chain. This is in agreement with the strong inequivalency observed for the $\mathrm{C} \mathrm{H}_{2}$ resonances of $\mathrm{K}^{3}$ at 3.45 and 2.77 p.p.m. (Figure 1a).

Clearly, several remaining resonances in the ${ }^{1} \mathrm{H}$ spectrum do not belong to the peptidic part. In particular, the doublet at 0.84 p.p.m. and the multiplet at 1.49 p.p.m. belong to an isopropyl group. By using both homonuclear and heteronuclear data, starting from the sole methyl signal of the spectrum, the $\left(\mathrm{CH}_{3}\right)_{2}-\mathrm{CH}-\left(\mathrm{CH}_{2}\right)_{3}-$ spin system was unambiguously characterized (Figure 2). This is also the case for the proton resonance at 3.81 p.p.m. that belongs to a $\mathrm{CH}$ group whose ${ }^{13} \mathrm{C}$ signal is at 67.58 p.p.m.. These chemical shifts are typical for an alcohol or ether function indicating the presence of an 
Table 1 Chemical structure characteristics of PAX and minimal inhibitory concentration (MIC) against bacteria and fungi including human pathogens

\begin{tabular}{|c|c|c|c|c|c|c|c|}
\hline & $P A X 1$ & $P A X 2$ & PAX 3 & PAX 4 & $P A X 5$ & Vancomycin & Polymixin $B$ \\
\hline Molecular weight (Da) & 1051 & 1079 & 1065 & 1093 & 1079 & & \\
\hline \multicolumn{8}{|l|}{ Chemical structure characteristics } \\
\hline Peptidic part: position 2 residue & $\mathrm{K}$ & $\mathrm{R}$ & K & $\mathrm{R}$ & ND & & \\
\hline 3-hydroxy fatty acid part: isomerization and length & iso- $14: 0$ & iso- $14: 0$ & iso- $15: 0$ & iso- $15: 0$ & & & \\
\hline \multicolumn{8}{|l|}{ Activity against Gram-negative bacteria } \\
\hline P. aeruginosa CIP 76.110 & $>100^{a}$ & $>100$ & 100 & 50 & 25 & $>100$ & 1.56 \\
\hline$P$. aeruginosa $\mathrm{H} 41308(\mathrm{~L}, \mathrm{Q})$ & $>100$ & $>100$ & 100 & 100 & 50 & $>100$ & 0.78 \\
\hline E. coli CIP 76.24 & 100 & $>100$ & 100 & 50 & 12.5 & $>100$ & 0.78 \\
\hline E. coli $\mathrm{H} 35393(\mathrm{~L}, \mathrm{C}, \mathrm{Q})^{\mathrm{b}}$ & $>100$ & 100 & 50 & 100 & 25 & $>100$ & 1.56 \\
\hline S. typhimurium $\mathrm{H} 23212$ & 100 & 100 & 100 & 100 & 50 & $>100$ & 1.56 \\
\hline S. maltophilia H38058 & $>100$ & $>100$ & $>100$ & $>100$ & $>100$ & 50 & 1.56 \\
\hline Klebsiella pneumoniae H35150 & $>100$ & $>100$ & $>100$ & $>100$ & $>100$ & $>100$ & 1.56 \\
\hline E. aerogenes $\mathrm{H} 35956$ & $>100$ & $>100$ & $>100$ & $>100$ & $>100$ & $>100$ & 1.56 \\
\hline M. morganii $\mathrm{H} 45543$ & $>100$ & $>100$ & $>100$ & $>100$ & $>100$ & $>100$ & $>100$ \\
\hline P. vulgaris CIP 58.60 & $>100$ & $>100$ & $>100$ & $>100$ & $>100$ & $>100$ & $>100$ \\
\hline \multicolumn{8}{|l|}{ Activity against Gram-positive bacteria } \\
\hline S. aureus CIP 76.25 & $>100$ & 100 & 50 & 50 & 50 & 1.56 & $>100$ \\
\hline S. epidermidis CIP 68.21 & 100 & 50 & 25 & 12.5 & 12.5 & 1.56 & 100 \\
\hline E. faecalis H37812 & $>100$ & $>100$ & $>100$ & $>100$ & $>100$ & 1.56 & $>100$ \\
\hline B. cereus ATCC 14579 & & & 25 & 25 & & 1.56 & $>100$ \\
\hline S. pneumoniae CIP 103.566 & $>100$ & $>100$ & $>100$ & $>100$ & $>100$ & 1.56 & $>100$ \\
\hline M. luteus CIP 53.45 & 3.125 & 3.125 & 3.125 & 3.125 & 1.56 & 0.78 & 6.25 \\
\hline \multicolumn{8}{|l|}{ Activity against fungi and yeast } \\
\hline F. oxysporum $\mathrm{H} 3012$ & 1.56 & 1.56 & 1.56 & 3.12 & 0.78 & & \\
\hline C. albicans CIP 48.72 & 50 & 50 & 50 & 50 & 50 & & \\
\hline
\end{tabular}

Abbreviation: ND, not determined.

aln $\mu \mathrm{g} \mathrm{ml}^{-1}$.

besistance to L: $\beta$ lactam, Q: quinolone, C: Cycline.

Table 2 Antifungal activity of PAX (percent inhibition of fungal growth)

\begin{tabular}{|c|c|c|c|c|c|c|c|c|c|}
\hline & \multicolumn{3}{|c|}{$P A X 1$} & \multicolumn{3}{|c|}{$P A X 2$} & \multicolumn{3}{|c|}{$P A X 3$} \\
\hline & $10 \mu g \mathrm{~m}^{-1}$ & $20 \mu \mathrm{g} \mathrm{m}^{-1}$ & $40 \mu \mathrm{gm}^{-1}$ & $10 \mu g \mathrm{~m}^{-1}$ & $20 \mu g \mathrm{~m}^{-1}$ & $40 \mu \mathrm{gml}^{-1}$ & $10 \mu \mathrm{g} \mathrm{m}^{-1}$ & $20 \mu \mathrm{g} \mathrm{m}^{-1}$ & $40 \mu \mathrm{g} \mathrm{m}^{-1}$ \\
\hline Alternaria brassicae & 82 & 84 & 83 & 25 & 47 & 83 & 82 & 82 & 83 \\
\hline Botrytis cinerea & 38 & 95 & 95 & 12 & 53 & 83 & 52 & 95 & 94 \\
\hline Botrytis cinerea myc & 21 & 34 & 60 & 0 & 6 & 34 & 40 & 70 & 93 \\
\hline Cladosporium sp & 94 & 94 & 94 & 74 & 95 & 95 & 94 & 94 & 94 \\
\hline Cladosporium myc & 89 & 90 & 89 & 0 & 40 & 91 & 70 & 92 & 91 \\
\hline F. culmorum & 96 & 96 & 96 & 66 & 97 & 97 & 96 & 96 & 96 \\
\hline Helminthosporium teres & 70 & 91 & 95 & 33 & 47 & 80 & 76 & 94 & 92 \\
\hline Rhizoctonia solani myc & 9.7 & 85 & 93 & 6 & 7 & 64 & 56 & 91 & 93 \\
\hline Phytophthora myc & 79 & 78 & 77 & 71 & 81 & 78 & 76 & 78 & 77 \\
\hline P. oryzae & 18 & 22 & 45 & 12 & 15 & 21 & 30 & 35 & 45 \\
\hline S. tritici & 88 & 88 & 85 & 0 & 86 & 89 & 87 & 88 & 86 \\
\hline
\end{tabular}

$-\mathrm{CH}(\mathrm{OH})$ - or $-\mathrm{CH}(\mathrm{OR})$ - group. In addition, from this alcohol or ether group the $\mathrm{CO}-\mathrm{CH}_{2}-\mathrm{CH}(\mathrm{O})-\left(\mathrm{CH}_{2}\right)_{3}$ - spin system was clearly characterized (Figure 2). Interestingly, these two well-identified spin systems share an identical intense cross-peak at $\left({ }^{1} \mathrm{H}\right) 1.24 /\left({ }^{13} \mathrm{C}\right)$
28.86 p.p.m. corresponding to several $-\mathrm{CH}_{2}$ - groups, suggesting that the two spin systems could be linked together by an aliphatic chain. Thus, the acyl fragment would be a 3-hydroxy fatty acid. Owing to the overlap of several methylene groups the acyl chain length was deduced 
Table 3 NMR data of PAX 3 (dimethyl sulfoxide, $32^{\circ}$ C) and of PAX 4 (dimethyl sulfoxide, $27^{\circ} \mathrm{C}$ )

\begin{tabular}{|c|c|c|c|c|}
\hline \multicolumn{3}{|c|}{ Pax 3} & \multicolumn{2}{|c|}{ Pax 4} \\
\hline Residue & ${ }^{13} \mathrm{C}$ (p.p.m.) & ${ }^{1} H$ (p.p.m.) & Residue & ${ }^{1} H$ (p.p.m.) \\
\hline \multicolumn{3}{|c|}{ iso-15:0 (3-hydroxy) fatty acid } & \multicolumn{2}{|c|}{ iso-15:0 (3-hydroxy) fatty acid } \\
\hline$\left(\mathrm{CH}_{3}\right) 2$ & 22.29 & 0.845 & $\left(\mathrm{CH}_{3}\right) 2$ & 0.841 \\
\hline $\mathrm{C}_{13} \mathrm{H}$ & 27.15 & 1.489 & $\mathrm{C}_{13} \mathrm{H}$ & 1.500 \\
\hline $\mathrm{C}_{12} \mathrm{H} 2$ & 38.21 & 1.140 & $\mathrm{C}_{12} \mathrm{H} 2$ & 1.135 \\
\hline $\mathrm{C}_{11} \mathrm{H} 2$ & 26.55 & 1.124 & $\mathrm{C}_{11} \mathrm{H} 2$ & 1.240 \\
\hline $\mathrm{C}_{6-10} \mathrm{H}_{2}$ & 28.86 & 1.249 & $\mathrm{C}_{6-10} \mathrm{H}_{2}$ & 1.250 \\
\hline $\mathrm{C}_{5} \mathrm{H} 2$ & 24.78 & 1.243 & $\mathrm{C}_{5} \mathrm{H} 2$ & 1.238 \\
\hline $\mathrm{C}_{4} \mathrm{H}_{2}$ & 36.78 & 1.356 & $\mathrm{C}_{4} \mathrm{H} 2$ & 1.354 \\
\hline $\mathrm{C}_{3} \mathrm{H}(\mathrm{OH})$ & 67.58 & 3.807 & $\mathrm{C}_{3} \mathrm{H}(\mathrm{OH})$ & 3.803 \\
\hline $\mathrm{C}_{2} \mathrm{H}_{2}$ & 43.25 & 2.233 & $\mathrm{C}_{2} \mathrm{H} 2$ & 2.228 \\
\hline $\mathrm{C}_{1} \mathrm{O}$ & 171.45 & & & \\
\hline \multicolumn{3}{|l|}{ Gly ${ }^{1}$} & \multicolumn{2}{|l|}{ Gly ${ }^{1}$} \\
\hline $\mathrm{HN}$ & & 8.178 & $\mathrm{HN}$ & 8.190 \\
\hline $\mathrm{H}_{\alpha}$ & 41.92 & 3.738 & $\mathrm{H}_{\alpha}$ & 3.755 \\
\hline $\mathrm{H}_{\alpha^{\prime}}$ & & 3.700 & $\mathrm{H}_{\alpha^{\prime}}$ & 3.688 \\
\hline \multicolumn{3}{|l|}{$L y s^{2}$} & \multicolumn{2}{|l|}{$\operatorname{Arg}^{2}$} \\
\hline $\mathrm{HN}$ & & 8.015 & $\mathrm{HN}$ & 8.063 \\
\hline $\mathrm{H}_{\alpha}$ & 52.68 & 4.180 & $\mathrm{H}_{\alpha}$ & 4.199 \\
\hline $\mathrm{C}_{\beta} \mathrm{H} 2$ & 30.41 & $1.615 / 1.557$ & $\mathrm{C}_{\beta} \mathrm{H} 2$ & $1.662 / 1.563$ \\
\hline $\mathrm{C}_{\gamma} \mathrm{H} 2$ & 21.96 & 1.320 & $\mathrm{C}_{\gamma} \mathrm{H} 2$ & $1.499 / 1.420$ \\
\hline $\mathrm{C}_{\delta} \mathrm{H} 2$ & 26.35 & 1.518 & $\mathrm{C}_{\delta} \mathrm{H} 2$ & 3.097 \\
\hline $\mathrm{C}_{\varepsilon} \mathrm{H} 2$ & 38.38 & 2.740 & $\mathrm{HN}_{\varepsilon}$ & 7.768 \\
\hline \multicolumn{3}{|l|}{$L y s^{3}$} & \multicolumn{2}{|l|}{$L y s^{3}$} \\
\hline $\mathrm{HN}$ & & 8.377 & $\mathrm{HN}$ & 8.423 \\
\hline $\mathrm{H}_{\alpha}$ & 53.53 & 4.093 & $\mathrm{H}_{\alpha}$ & 4.104 \\
\hline $\mathrm{C}_{\beta} \mathrm{H} 2$ & 30.77 & 1.653 & $\mathrm{C}_{\beta} \mathrm{H} 2$ & 1.646 \\
\hline $\mathrm{C}_{\gamma} \mathrm{H} 2$ & 22.18 & 1.430 & $\mathrm{C}_{\gamma} \mathrm{H} 2$ & $1.325 / 1.233$ \\
\hline $\mathrm{C}_{\delta} \mathrm{H} 2$ & 28.68 & $1.455 / 1.324$ & $\mathrm{C}_{\delta} \mathrm{H} 2$ & 1.420 \\
\hline $\mathrm{C}_{\varepsilon} \mathrm{H} 2$ & 37.95 & $3.448 / 2.774$ & $\mathrm{C}_{\varepsilon} \mathrm{H} 2$ & $3.458 / 2.756$ \\
\hline $\mathrm{HN}_{\varepsilon}$ & & 7.358 & $\mathrm{H}_{\varepsilon} \mathrm{N}$ & 7.353 \\
\hline \multicolumn{3}{|l|}{ Lys $^{4}$} & \multicolumn{2}{|l|}{ Lys ${ }^{4}$} \\
\hline $\mathrm{HN}$ & & 7.589 & $\mathrm{HN}$ & 7.600 \\
\hline $\mathrm{H}_{\alpha}$ & 52.76 & 4.097 & $\mathrm{H}_{\alpha}$ & 4.087 \\
\hline $\mathrm{C}_{\beta} \mathrm{H} 2$ & 29.68 & $1.656 / 1.628$ & $\mathrm{C}_{\beta} \mathrm{H} 2$ & 1.645 \\
\hline $\mathrm{C}_{\gamma} \mathrm{H} 2$ & 21.67 & 1.213 & $\mathrm{C}_{\gamma} \mathrm{H} 2$ & $1.293 / 1.212$ \\
\hline $\mathrm{C}_{\delta} \mathrm{H} 2$ & 26.25 & 1.518 & $\mathrm{C}_{\delta} \mathrm{H} 2$ & 1.517 \\
\hline $\mathrm{C}_{\varepsilon} \mathrm{H} 2$ & 38.38 & 2.740 & $\mathrm{C}_{\varepsilon} \mathrm{H} 2$ & 2.750 \\
\hline \multicolumn{3}{|l|}{$\operatorname{Lys}^{5}$} & \multicolumn{2}{|l|}{$L y s^{5}$} \\
\hline $\mathrm{HN}$ & & 8.165 & $\mathrm{HN}$ & 8.174 \\
\hline $\mathrm{H}_{\alpha}$ & 52.86 & 4.073 & $\mathrm{H}_{\alpha}$ & 4.064 \\
\hline $\mathrm{C}_{\beta} \mathrm{H} 2$ & 30.52 & 1.750 & $\mathrm{C}_{\beta} \mathrm{H} 2$ & $1.745 / 1.590$ \\
\hline $\mathrm{C}_{\gamma} \mathrm{H} 2$ & 21.69 & 1.320 & $\mathrm{C}_{\gamma} \mathrm{H} 2$ & 1.321 \\
\hline $\mathrm{C}_{\delta} \mathrm{H} 2$ & 26.25 & & $\mathrm{C}_{\delta} \mathrm{H} 2$ & 1.543 \\
\hline $\mathrm{C}_{\varepsilon} \mathrm{H} 2$ & 38.38 & 2.740 & $\mathrm{C}_{\varepsilon} \mathrm{H} 2$ & 2.740 \\
\hline \multicolumn{3}{|l|}{$\operatorname{Lys}^{6}$} & \multicolumn{2}{|l|}{$\operatorname{Lys}^{6}$} \\
\hline $\mathrm{HN}$ & & 7.922 & $\mathrm{HN}$ & 7.926 \\
\hline $\mathrm{H}_{\alpha}$ & 52.15 & 4.077 & $\mathrm{H}_{\alpha}$ & 4.064 \\
\hline $\mathrm{C}_{\beta} \mathrm{H} 2$ & 29.35 & $1.765 / 1.512$ & $\mathrm{C}_{\beta} \mathrm{H} 2$ & 1.700 \\
\hline $\mathrm{C}_{\gamma} \mathrm{H} 2$ & 22.02 & $1.318 / 1.264$ & $\mathrm{C}_{\gamma} \mathrm{H} 2$ & 1.324 \\
\hline $\mathrm{C}_{\delta} \mathrm{H} 2$ & 26.23 & 1.518 & $\mathrm{C}_{\delta} \mathrm{H} 2$ & 1.525 \\
\hline $\mathrm{C}_{\varepsilon} \mathrm{H} 2$ & 38.38 & 2.740 & $\mathrm{C}_{\varepsilon} \mathrm{H} 2$ & 2.760 \\
\hline
\end{tabular}

Table 3 Continued

\begin{tabular}{|c|c|c|c|c|}
\hline \multicolumn{3}{|c|}{ Pax 3} & \multicolumn{2}{|c|}{ Pax 4} \\
\hline Residue & ${ }^{13} \mathrm{C}$ (p.p.m.) & ${ }^{1} H$ (p.p.m.) & Residue & ${ }^{1} H$ (p.p.m.) \\
\hline $\operatorname{Lys}^{7}$ & & & $\mathrm{Lys}^{7}$ & \\
\hline $\mathrm{HN}$ & & 7.904 & $\mathrm{HN}$ & 7.926 \\
\hline $\mathrm{H}_{\alpha}$ & 53.23 & 4.077 & $\mathrm{H}_{\alpha}$ & 4.064 \\
\hline $\mathrm{C}_{\beta} \mathrm{H} 2$ & 30.04 & $1.717 / 1.640$ & $\mathrm{C}_{\beta} \mathrm{H} 2$ & 1.700 \\
\hline $\mathrm{C}_{\gamma} \mathrm{H} 2$ & 22.12 & 1.378 & $\mathrm{C}_{\gamma} \mathrm{H} 2$ & 1.324 \\
\hline $\mathrm{C}_{\delta} \mathrm{H} 2$ & 26.23 & 1.518 & $\mathrm{C}_{\delta} \mathrm{H} 2$ & 1.525 \\
\hline $\mathrm{C}_{\varepsilon} \mathrm{H} 2$ & 38.38 & 2.740 & $\mathrm{C}_{\varepsilon} \mathrm{H} 2$ & 2.762 \\
\hline
\end{tabular}

from the molecular weight as being an iso-15:0 3-hydroxy fatty acid. Moreover, the 'sequential' NOE between the $\mathrm{C}_{2} \mathrm{H}_{2}$ (2.23 p.p.m.) of the 3-hydroxy fatty acid and the amide proton of $\mathrm{G}^{1}$ unambiguously characterized the amide bond link between the fatty acid and the peptidic fragments. Finally, the PAX 3 structure was fully corroborated by MS-MS fragmentation (Figure 3 ).

Altogether, these data suggest the presence of the iso-15:0 3-hydroxy fatty acid linked to the cyclopeptidic part at the $\mathrm{G}^{1}$ residue to yield a lysine-rich cyclolipopeptide with a 5-residue macrolactame ring (Figure 4). The configurations of the $\alpha$-carbons of the amino acids as well as that of the $C_{3}$ of the iso-15:0 3 hydroxy acid were not determined.

The PAX 1, PAX 2 and PAX 4, ${ }^{1} \mathrm{H}$ NMR spectra in DMSO (dimethyl sulfoxide) were very similar to that of PAX 3. The two main changes were easily observed and characterized by the combination of ${ }^{1} \mathrm{H}$ NMR and ESI/MS data. The first one with regard to the peptidic part with the $\mathrm{K}^{2} \mathrm{R}$ mutation, whereas the second one with regard to the length of the fatty acid. The PAX 2 (1079 Da) and PAX 4 (1093 Da) chemical structures consist of the $\mathrm{K}^{2} \mathrm{R}$ mutation (Tables 1 and 3) with the iso-14:0 and the iso-15:0 3-hydroxy acid, respectively. In contrast, PAX $1(1051 \mathrm{Da})$ displays a $\mathrm{K} 2$ residue and the iso-14:0 3-hydroxy acid.

Although the ${ }^{1} \mathrm{H}$ NMR spectrum of PAX 5 could not be obtained, its molecular weight identical to PAX $2(1079 \mathrm{Da})$ suggested that it could be its normal isomer. However, when compared with PAX 3, the $+14 \mathrm{Da}$ delta mass could be explained either by one methylene group extension of the 3-hydroxy fatty acid to yield a 16:0 homolog or by a simultaneous presence of a K2R mutation (+28 Da) and a 14:0 3hydroxy fatty acid $(-14 \mathrm{Da})$. To choose between these two hypothesis, more material should be isolated to record the PAX 5 NMR spectrum.

Notice that in cyclolipopeptides there are two types of cyclizations involving the carboxylic group, one involving an amide bond and another an ester bond leading to a macrolactame or a macrolactone ring, respectively. ${ }^{37}$

\section{Conclusion}

This report describes the production, the purification and the characterization of a new antimicrobial family from $X$. nematophila. Their significant antifungal activity and their lack of cytotoxicity and entomotoxicity increase the potential interest of these molecules for vegetal or human health application.

\section{METHODS}

\section{Producing organism}

Xenorhabdus nematophila F1 (Ecologie Microbienne des Insectes et Interactions Hôtes-Pathogène collection) was grown on Luria-Bertani medium (LB, 


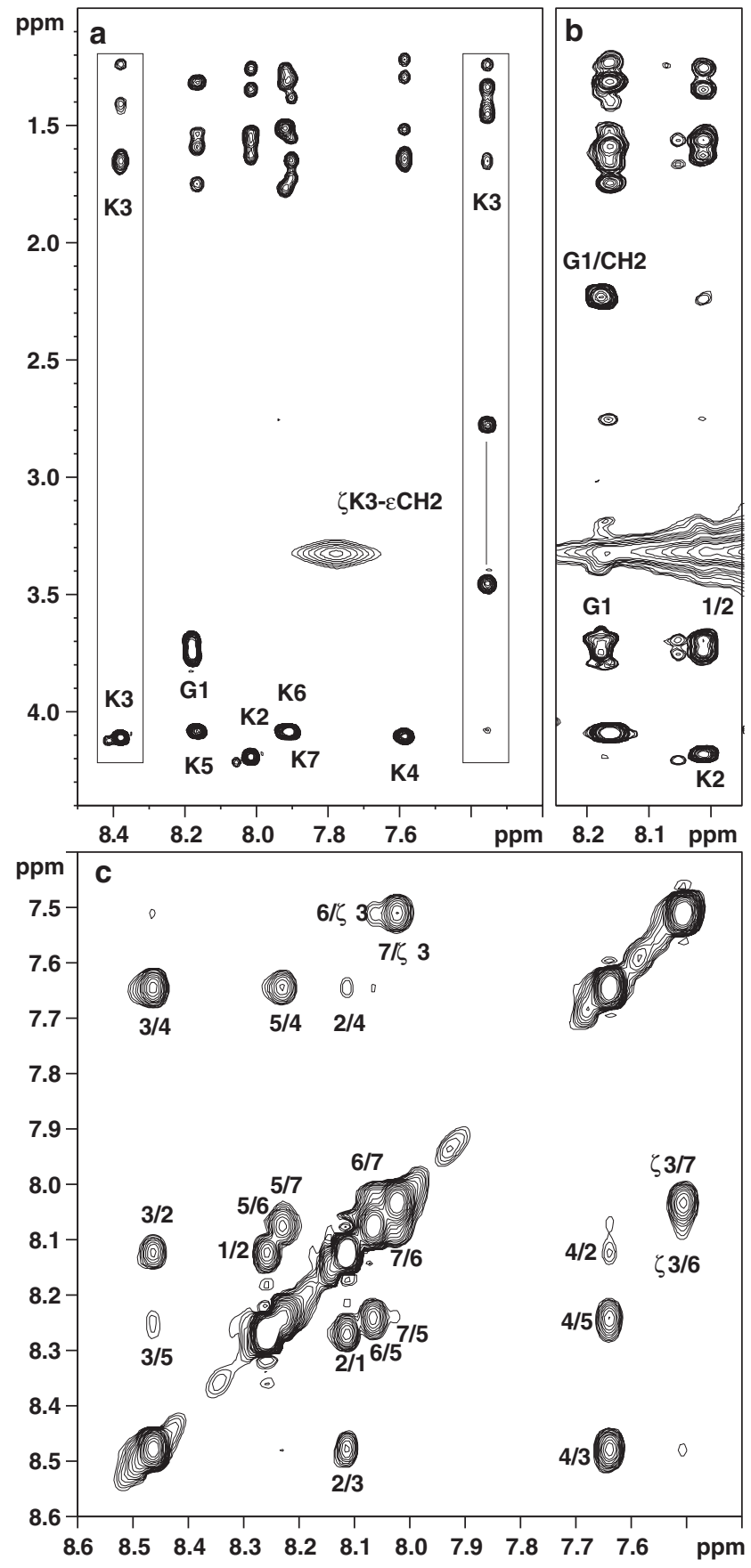

Figure $1^{1} \mathrm{H}$ NMR data illustrating the assignment of the peptidic moiety. (a) Part of the TOCSY showing the different spin systems (DMSO, 305 K). $\zeta \mathrm{K}^{3}$ is for the zeta amide proton of $\mathrm{K}^{3}$. The side chain spin system of $\mathrm{K}^{3}$ observed both from the amide and the $\zeta \mathrm{K}^{3}$ amide proton is boxed. Due to the length of the side chain the $\varepsilon \mathrm{CH}_{2}$ cross-peaks are of weak intensity from the amide chemical shift and not observed in this plot level. (b) Part of the NOESY showing the 'sequential' NOE between the $\alpha \mathrm{CH}_{2}$ of the fatty acid and the amide proton of $\mathrm{G}^{1}$ labeled $\mathrm{G}^{1} / \mathrm{CH}_{2}$ (DMSO- $d 6,305 \mathrm{~K}, 250 \mathrm{~ms}$ of mixing time). (c) Part of the NOESY showing the dNN NOEs (DMSO-d6 with $17 \%$ of water, $285 \mathrm{~K}, 250 \mathrm{~ms}$ of mixing time). The strong intensity NOE between $\mathrm{HN} \mathrm{K}^{7}$ and $\zeta \mathrm{HN} \mathrm{K}^{3}$ amide protons (7//3) characterizes the cyclization. Notice that the dNN6-7 was not observed in pure DMSO due to the overlap of the $\mathrm{K}^{6}$ and $\mathrm{K}^{7}$ amide signals (part a).

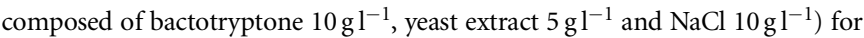
liquid culture and on LB-agar for solid cultures. The phase status (I or II) of this strain was determined by culturing on NBTA (Nutrient agar (Difco,

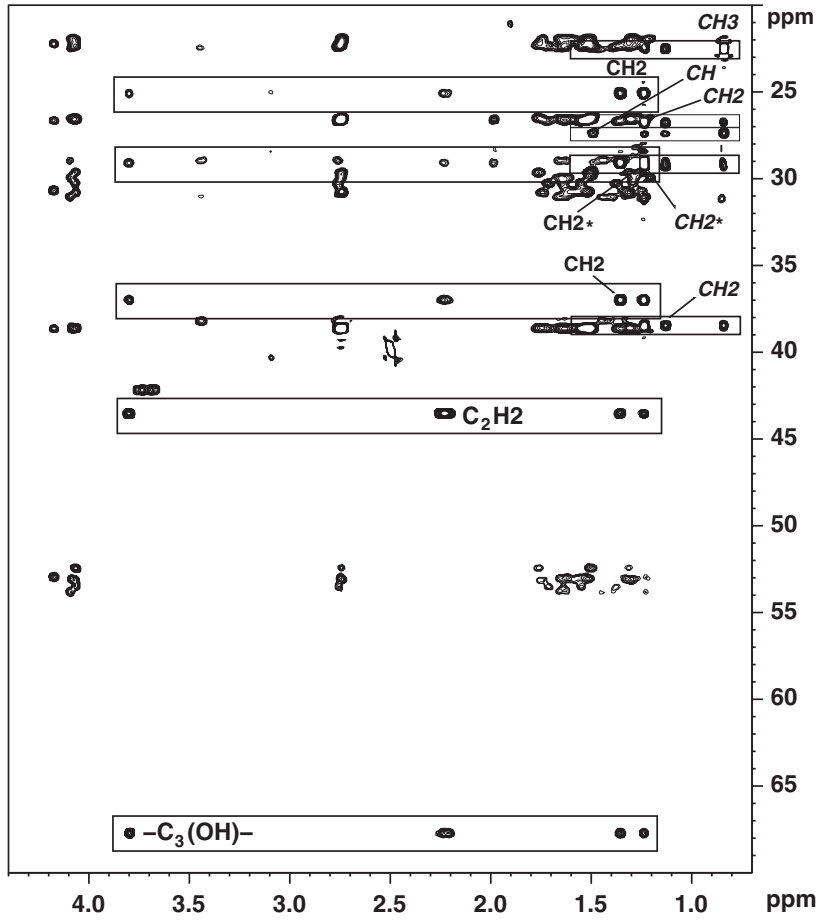

Figure 2 Part of the ${ }^{1} \mathrm{H}_{-}{ }^{13} \mathrm{C}$ HSQC-TOCSY showing the spin system of the iso-15:0 3-hydroxy fatty acid. The two partial spin systems identified from the carboxyl (large rectangles) and from the methyl (small rectangles with labels in italics) groups are boxed. They share the same $\mathrm{CH}_{2}$ cross-peak (twofold labeled $\mathrm{CH}_{2}{ }^{*}$ ) corresponding to the overlap of several equivalent methylene groups at $1.24 / 28.86$ p.p.m. located between the two extremities of the fatty acid. The length of the acyl chain was deduced from the molecular weight obtained by mass spectrometry.

Detroit, MI, USA) $31 \mathrm{gl}^{-1}$, bromothymol blue $25 \mathrm{mgl}^{-1}$ and 2, 3, 5-triphenyl tetrazolium chloride $1 \% 40 \mathrm{mgl}^{-1}$ ) and measuring antibacterial activity against M. luteus. Xenorhabdus exhibits two colony forms or variants when cultured in vitro. Modifications of the outer membrane induce differential adsorption of dyes by variants. Phase I variants absorb dyes and are blue on NBTA plates, whereas phase II colonies are red. Phases I and II of strains are indicated as suffixes (/1 and $/ 2$, respectively) attached to strain designations. This strain was maintained at $15^{\circ} \mathrm{C}$ on NBTA medium.

\section{Bacterial strains and antimicrobial agents}

The following reference strains were used for the evaluation of antimicrobial activity: P. aeruginosa CIP 76.110, E. coli CIP 76.24, Proteus vulgaris CIP 58.60, S. aureus CIP 76.25, S. epidermidis CIP 68.21, Bacillus cereus ATCC 14579, Streptococcus pneumoniae CIP 103.566, M. luteus CIP 53.45 and C. albicans CIP 48.72 and clinical isolates (strains are indicated as suffixes $\mathrm{H}$ and a number) obtained from patients with infection at the University Hospital of Nîmes. Phytopathogenic fungi were obtained from Rhobio (Lyon, France). Vancomycin and polymyxin (Sigma-Aldrich, St Louis, MO, USA) were provided as standard powders by the manufacturers.

\section{Antibacterial susceptibility testing methods}

The minimal inhibitory concentration (MIC) was defined as the lowest antibiotic concentration, which yielded no visible growth. MIC was determined as recommended by the Clinical and Laboratory Standards Institute. ${ }^{38}$ Antibiotics were tested at final concentrations (prepared from serial twofold dilutions) ranging from 100 to $0.78 \mathrm{mgl}^{-1}$. The test medium was MuellerHinton broth, and the inoculum was $5 \times 10^{5} \mathrm{CFU} \mathrm{ml}^{-1}$. The inoculated microplates were incubated at $37^{\circ} \mathrm{C}$ under shaking for $18 \mathrm{~h}$ before reading. 


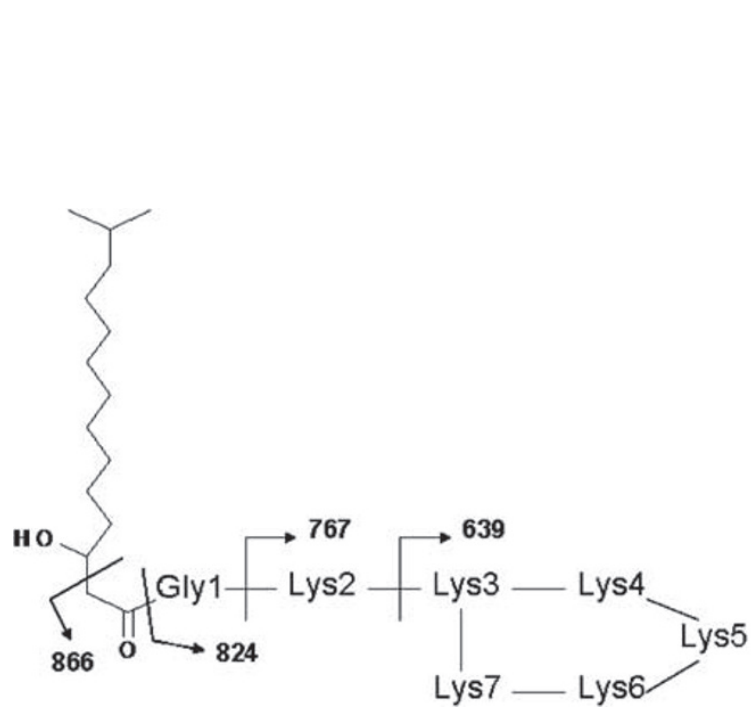

Figure 3 Key fragmentations of the $1066[\mathrm{M}+\mathrm{H}]^{+}$ions of PAX 3.

\section{Antifungal susceptibility testing methods}

The PAX activities were tested against the human pathogen F. oxysporum and against different phytopathogenic fungi by the M38-A microdilution method ${ }^{39}$ with RPMI 1640 medium as recommended in the Clinical and Laboratory Standards Institute M23-A document. ${ }^{40}$ The NCCLS M27-A2 broth microdilution method was used when C. albicans was tested. ${ }^{41}$

Fungal inoculi were prepared from 7-day cultures grown on potato dextrose agar and adjusted spectrophotometrically to optical densities that ranged from 0.09 to 0.17 and diluted (1:50) in RPMI 1640 broth. The density of the inoculum suspension of C. albicans isolate was adjusted to a density of a 0.5 McFarland standard and diluted 1:1000 in RPMI 1640 broth. ${ }^{41}$ Microdilution trays (96 U-bottom shaped) containing $100 \mu \mathrm{l}$ antifungal dilutions were added with $100 \mu \mathrm{l}$ PAX solutions (final concentration ranging from 100 to $0.78 \mathrm{mgl}^{-1}$ for F. oxysporum and C. albicans; 10,20 and $40 \mu \mathrm{g} \mathrm{ml}^{-1}$ for other fungi). After inoculation of the trays, all microdilution trays were incubated at $30{ }^{\circ} \mathrm{C}$ in ambient air. As described in the M38-A method, ${ }^{39}$ MICs for F. oxysporum were determined by visual examination at $48 \mathrm{~h}$. MICs were defined as the lowest drug concentration that showed absence of growth or complete growth inhibition (100\%). MICs for C. albicans were determined at $48 \mathrm{~h}$ and corresponded to $100 \%$ of growth inhibition. ${ }^{41}$ Regarding phytopathogenic fungi, the culture absorbance was measured at $600 \mathrm{~nm}, 5$ days after the beginning of the experiments. The activity results correspond to a percentage of growth inhibition $\left(\left(1-\mathrm{Abs}_{600 \mathrm{~nm}}\right.\right.$ culture with $\left.\mathrm{PAX}\right) / \mathrm{Abs}_{600 \mathrm{~nm}}$ culture without PAX).

\section{Cytotoxicity test}

Chinese Hamster Ovary $(\mathrm{CHO})$ cells were grown in RPMI medium supplemented with $5 \%(\mathrm{v} / \mathrm{v})$ fetal calf serum. The cells were incubated for $24 \mathrm{~h}$ at $37^{\circ} \mathrm{C}$ in the absence of serum and in the presence of PAX (final concentration ranging from 1000 to $7.8 \mathrm{mgl}^{-1}$ ).

The cytotoxicity was measured using the cell cytotoxicity Kit I (Roche Applied Sciences, Meylan, France).

\section{Insect toxicity tests}

The common cutworm, Spodoptera littoralis, was reared on an artificial diet ${ }^{42}$ at $24^{\circ} \mathrm{C}$, and the wax moth, Galleria mellonella, was reared on pollen and wax at

\begin{tabular}{|c|c|}
\hline \multicolumn{2}{|c|}{ Fragment ion } \\
\hline 129 & {$\left[\text { Lys }^{7}+\mathrm{H}\right]^{+}$} \\
\hline 185 & {$\left[\text { Gly }^{1} \text { Lys }^{2}+\mathrm{H}\right]^{+}$} \\
\hline 257 & {$\left[\text { Lys }^{7} \text { Lys }^{6}+\mathrm{H}\right]^{+}$} \\
\hline 385 & {$\left[\text { Lys }^{7} \text { Lys }^{6} \text { Lys }^{5}+\mathrm{H}\right]^{+}$} \\
\hline 513 & {$\left[\text { Lys }^{7} \text { Lys }^{6} \text { Lys }^{5} \text { Lys }^{4}+\mathrm{H}\right]^{+}$} \\
\hline 554 & {$[\mathrm{M}+\mathrm{H}]^{+}-$Lys $^{7}$ Lys $^{6}$ Lys $^{5}$ Lys $^{4}$} \\
\hline 639 & figure \\
\hline 641 & {$\left[\text { Lys }^{7} \text { Lys }^{6} \text { Lys }^{5} \text { Lys }^{4} \text { Lys }^{3}+\mathrm{H}\right]^{+}$} \\
\hline 682 & {$[\mathrm{M}+\mathrm{H}]^{+}-$Lys $^{7}$ Lys $^{6}$ Lys $^{5}$} \\
\hline 767 & figure \\
\hline 769 & {$\left[\text { Lys }^{7} \text { Lys }^{6} \text { Lys }^{5} \text { Lys }^{4} \text { Lys }^{3} \text { Lys }^{2}+\text { H }\right]^{+}$} \\
\hline 810 & {$[\mathrm{M}+\mathrm{H}]^{+}-$Lys $^{7} \mathrm{Lys}^{6}$} \\
\hline 824 & figure \\
\hline 826 & {$\left[\text { Lys }^{7} \text { Lys }^{6} \text { Lys }^{5} \text { Lys }^{4} \text { Lys }^{3} \text { Lys }^{2} \text { Gly }^{1}+H\right]^{+}$} \\
\hline 866 & figure \\
\hline 938 & {$[\mathrm{M}+\mathrm{H}]^{+}-\mathrm{Lys}^{7}$} \\
\hline 1048 & {$[\mathrm{M}+\mathrm{H}]^{+}-\mathrm{H}_{2} \mathrm{O}$} \\
\hline
\end{tabular}

$28^{\circ} \mathrm{C}$. A locust, Locusta migratoria, was reared on grass at $28^{\circ} \mathrm{C}$. Eggs of the tobacco hornworm, Manduca sexta, were obtained from Monika Stengl (University of Regensburg, Regensburg, Germany). M. sexta larvae were reared on an artificial diet ${ }^{43}$ at $27^{\circ} \mathrm{C}$ with light-dark cycles consisting of $16 \mathrm{~h}$ of light and $8 \mathrm{~h}$ of darkness. Fifth-instar larvae of each insect species were selected and surface sterilized with $70 \%(\mathrm{v} / \mathrm{v})$ ethanol before intrahemocoelic injection. The larvae were divided into groups of 12 larva, and each larva was injected with $10 \mu \mathrm{l}$ of one of the purified PAX, corresponding to a dose of $0.1 \mu \mathrm{g}$ per insect, or with phosphate-buffered saline. The treated larvae were incubated individually for up to $96 \mathrm{~h}$, and then the number of dead insects was recorded.

A liquid hemolysis assay with sheep erythrocytes ${ }^{44}$ was used to determine hemolytic activity of purified PAX. Cytolytic assays were performed with insect hemocytes by collecting hemolymph samples from $S$. littoralis larvae in an anticoagulant buffer. ${ }^{45}$ Hemocytes were centrifuged, rinsed in phosphatebuffered saline to remove plasmatic factors, and resuspended in the same buffer $\left(2 \times 10^{4}\right.$ hemocytes $\left.\mathrm{ml}^{-1}\right)$. The suspensions $(10 \mu \mathrm{l})$ were each mixed with $10 \mu \mathrm{l}$ of a purified PAX, corresponding to a $0.1-\mu \mathrm{g}$ dose, deposited on a slide, and incubated for $20 \mathrm{~min}$ at $28^{\circ} \mathrm{C}$. Hemocytes with phosphate-buffered saline were used as a control. Cell lysis was observed with a light microscope and was recorded.

\section{NMR and MS analysis}

The NMR samples were prepared from the lyophylized lipopeptide. They were disolved in DMSO- $d 6$ to yield $1.0-1.5 \mathrm{~mm}$ solution. Chemical shifts are expressed with respect to the DMSO-d6 residual signal set at 2.50 and 39.5 p.p.m. for ${ }^{1} \mathrm{H}$ and ${ }^{13} \mathrm{C}$ spectra, respectively. All NMR experiments were carried out on a Bruker Avance 600 spectrometer (Bruker Analytik GmbH, Rheinstetten, Germany) equipped with a triple resonance cryoprobe, and spectra were recorded at temperatures ranging from 295 to $310 \mathrm{~K}$. Doublequantum filtered-COSY (DQF-COSY), ${ }^{46,47} \mathrm{z}$-filtered total-correlated spectroscopy (z-TOCSY $)^{48,49}$ and NOESY ${ }^{50}$ spectra were acquired in the phasesensitive mode, using the States-TPPI method. ${ }^{51}$ We obtained $z$-TOCSY spectra with a mixing time of $90 \mathrm{~ms}$ and NOESY spectra with mixing times of 150 and $250 \mathrm{~ms}$, respectively. The ${ }^{1} \mathrm{H}_{-}{ }^{15} \mathrm{~N}$ HSQC, ${ }^{1} \mathrm{H}_{-}-{ }^{13} \mathrm{C}$ HSQC, ${ }^{1} \mathrm{H}_{-}{ }^{13} \mathrm{C}$ HMBC, ${ }^{1} \mathrm{H}_{-}{ }^{13} \mathrm{C}$ HSQC-TOCSY experiments ${ }^{52-54}$ were carried out with the same sample. 


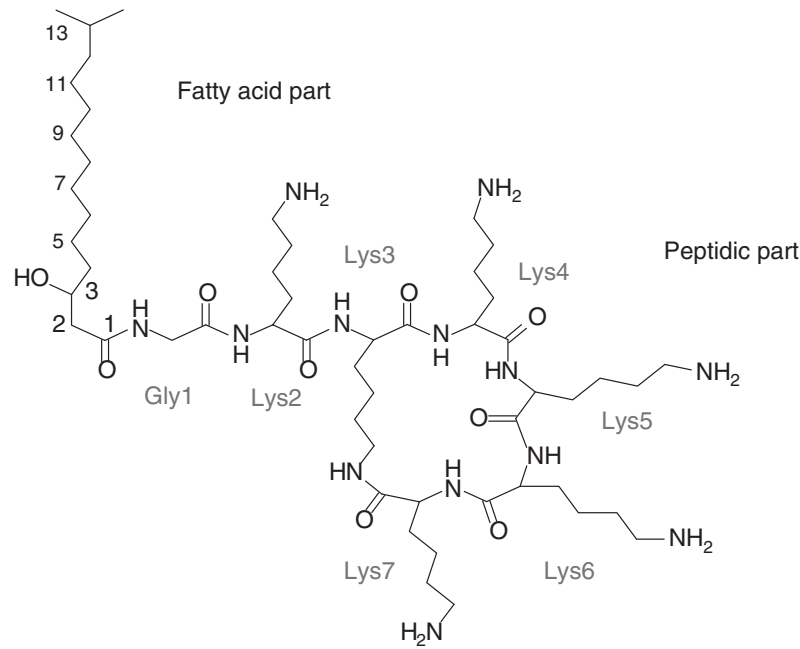

Figure 4 Chemical structure of PAX 3.

All data were processed with XWINNMR software (Bruker Analytik GmbH). The assignment of the peptidic part was achieved using the general strategy described by Wüthrich. ${ }^{55}$ Owing to the close proximity of the $\mathrm{K}^{6}$ and $\mathrm{K}^{7}$ amide signals in DMSO- $d 6$, the $\mathrm{dNN}_{6-7} \mathrm{NOE}$ could not be observed. Thus, two other data sets were recorded with 17 and $33 \%$ of water at several temperatures ranging from 285 to $310 \mathrm{~K}$. In these conditions, these two amide signals were enough separated to observe the $\mathrm{dNN}_{6-7} \mathrm{NOE}$.

The assignment of the non-peptidic part was obtained from the analysis of the homo and heteronuclear data. Owing to the overlap of ${ }^{1} \mathrm{H}$ resonances as well as the ${ }^{13} \mathrm{C}$ resonances of the central methylene groups of the fatty acid, giving rise to an unique HSQC cross-peak, the length of the fatty acid chain was calculated to be in agreement with the molecular weight measured by mass spectrometry. For PAX 1, 2 and 4, only ${ }^{1} \mathrm{H}-\mathrm{NMR}$ data were recorded.

LC-MS was first performed to obtain the $m / z$ value of the protonated PAX derivatives. ESI-LC-MS data were obtained in the positive mode on a Waters alliance LC-MS system (Waters ZQ mass detector, Waters photodiode array detector 2696, Waters alliance HPLC systems 2790). The HPLC column used was a C18 column (Waters; X-terra RP18; $5 \mu \mathrm{m} ; 4.6 \times 250 \mathrm{~mm}$ ) maintained at $35^{\circ} \mathrm{C}$. Solvents were (A) water $+0.1 \%$ TFA (B) acetonitrile $+0.1 \%$ TFA and the flow rate was $1 \mathrm{ml} \mathrm{min}^{-1}$. The mobile phase composition was $80 \%$ A from 0 to $5 \mathrm{~min}$, ramped to $80 \% \mathrm{~B}$ at $35 \mathrm{~min}$. Samples were dissolved in solvent A $(100 \mu \mathrm{l})$. Sample injection volume was $10 \mu \mathrm{l}$. UV-visible detection was by absorbance at $200-600 \mathrm{~nm}$. Solvent flow to the MS was diverted to waste for the first $5 \mathrm{~min}$ to minimize salt build-up. PAX 3 MS-MS fragmentation data were obtained on a Waters Micromass Q-T of micro mass spectrometer.

1 Poinar, G. O. J. The presence of Achromobacter nematophilus in the infective stage of a Neoaplectana sp. (Steinernematidae: Nematoda). Nematologica 12, 105-108 (1966).

2 Akhurst, R. J. Neoaplectana species: Specificity of association with bacteria of the genus Xenorhabdus. Exp. Parasitol. 55, 258-263 (1983).

3 Herbert, E. E. \& Goodrich-Blair, H. Friend and foe: the two faces of Xenorhabdus nematophila. Nat. Rev. Microbiol. 5, 634-646 (2007).

4 Kaya, H. K. \& Gaugler, R. Entomopathogenic nematodes. Ann. Rev. Entomol. 38, 181-206 (1993).

5 Brown, S. E. et al. Txp40, a ubiquitous insecticidal toxin protein from Xenorhabdus and Photorhabdus bacteria. Appl. Environ. Microbiol. 72, 1653-1662 (2006).

6 Park, Y. \& Kim, Y. Eicosanoids rescue Spodoptera exigua infected with Xenorhabdus nematophilus, the symbiotic bacteria to the entomopathogenic nematode Steinernema carpocapsae. J. Insect. Physiol. 46, 1469-1476 (2000).

7 Park, Y., Kim, Y. \& Stanley, D. The bacterium Xenorhabdus nematophila inhibits phospholipases A2 from insect, prokaryote, and vertebrate sources. Naturwissenschaften 91, 371-373 (2004).

8 Vigneux, F. et al. The xaxAB genes encoding a new apoptotic toxin from the insect pathogen Xenorhabdus nematophila are present in plant and human pathogens. J. Biol. Chem. 282, 9571-9580 (2007).
9 Forst, S., Dowds, B., Boemare, N. \& Stackebrandt, E. Xenorhabdus and Photorhabdus spp.: bugs that kill bugs. Annu. Rev. Microbiol. 51, 47-72 (1997).

10 Webster, J. M., Chen, G., Hu, K. \& Li, J. Bacterial metabolites. In Entomopathogenic Nematology (ed. Gangler, R.) 99-114 (CABI Publishing, New York, 2002).

11 Boemare, N. E., Boyer-Giglio, M. H., Thaler, J. O., Akhurst, R. J. \& Brehelin, M. Lysogeny and bacteriocinogeny in Xenorhabdus nematophilus and other Xenorhabdus spp. Appl. Environ. Microbiol. 58, 3032-3037 (1992).

12 Mclnerney, B. V. et al. Biologically active metabolites from Xenorhabdus spp., Part 1. Dithiolopyrrolone derivatives with antibiotic activity. J. Nat. Prod. 54, 774-784 (1991).

13 Mclnerney, B. V., Taylor, W. C., Lacey, M. J., Akhurst, R. J. \& Gregson, R. P. Biologically active metabolites from Xenorhabdus spp., Part 2. Benzopyran-1-one derivatives with gastroprotective activity. J. Nat. Prod. 54, 785-795 (1991).

$14 \mathrm{Li}$, J., Chen, G., Webster, J. M. \& Czyzewska, E. Antimicrobial metabolites from a bacterial symbiont. J. Nat. Prod. 58, 1081-1086 (1995).

$15 \mathrm{Li}$, J., Chen, G. \& Webster, J. M. Nematophin, a novel antimicrobial substance produced by Xenorhabdus nematophilus (Enterobactereaceae). Can. J. Microbiol. 43, 770-773 (1997)

16 Webster, J. M., Chen, G., Hu, K. \& Li, J. Bacterial metabolites. Entomopathogenic Nematology 99-114 (2002).

$17 \mathrm{Ji}$, D. et al. Identification of an antibacterial compound, benzylideneacetone, from Xenorhabdus nematophila against major plant-pathogenic bacteria. FEMS Microbiol. Lett. 239, 241-248 (2004).

18 Thaler, J. O., Baghdiguian, S. \& Boemare, N. Purification and characterization of xenorhabdicin, a phage tail-like bacteriocin, from the lysogenic strain F1 of Xenorhabdus nematophilus. Appl. Environ. Microbiol. 61, 2049-2052 (1995).

19 Lang, G., Kalvelage, T., Peters, A., Wiese, J. \& Imhoff, J. F. Linear and cyclic peptides from the entomopathogenic bacterium Xenorhabdus nematophilus. J. Nat. Prod. 71, 1074-1077 (2008).

20 Akhurst, R. J. Morphological and functional dimorphism in Xenorhabdus spp., bacteria symbiotically associated with the insect pathogenic nematodes Neoplectana and Heterorhabditis. J. Gen. Microbiol. 121, 303-309 (1980).

21 Boemare, N. E. \& Akhurst, R. J. Biochemical and physiological characterization of colony form variants in Xenorhabdus spp. (Enterobacteriaceae). J. Gen. Microbiol. 134, 751-761 (1988).

22 De Lucca, A. J. \& Walsh, T. J. Antifungal peptides: novel therapeutic compounds against emerging pathogens. Antimicrob. Agents Chemother. 43, 1-11 (1999).

23 Fiechter, A. Biosurfactants: moving towards industrial application. Trends Biotechnol. 10, 208-217 (1992).

24 Raaijmakers, J. M., de Bruijn, I. \& de Kock, M. J. Cyclic lipopeptide production by plant-associated Pseudomonas spp.: diversity, activity, biosynthesis, and regulation. Mol. Plant. Microbe Interact. 19, 699-710 (2006).

25 Jeu, L. \& Fung, H. B. Daptomycin: a cyclic lipopeptide antimicrobial agent. Clin. Ther. 26, 1728-1757 (2004).

26 Evans, M. E., Feola, D. J. \& Rapp, R. P. Polymyxin B sulfate and colistin: old antibiotics for emerging multiresistant Gram-negative bacteria. Ann. Pharmacother. 33, 960-967 (1999).

27 Sauermann, R., Rothenburger, M., Graninger, W. \& Joukhadar, C. Daptomycin: a review 4 years after first approval. Pharmacology 81, 79-91 (2008).

28 Danner, R. L. et al. Purification, toxicity, and antiendotoxin activity of polymyxin B nonapeptide. Antimicrob. Agents Chemother. 33, 1428-1434 (1989).

29 Denning, D. W. Echinocandins: a new class of antifungal. J. Antimicrob. Chemother. 49, 889-891 (2002).

30 Weis, F., Beiras-Fernandez, A. \& Schelling, G. Daptomycin, a lipopeptide antibiotic in clinical practice. Curr. Opin. Investig. Drugs 9, 879-884 (2008).

31 Denning, D. W. Echinocandin antifungal drugs. Lancet 362, 1142-1152 (2003).

32 Nelson, P. E., Dignami, M. C. \& Anaissie, E. J. Taxonomy, biology, and clinical aspects of Fusarium species. Clin. Microbiol. Rev. 7, 479-504 (1994).

33 Boutati, E. I. \& Anaissie, E. J. Fusarium, a significant emerging pathogen in patients with hematologic malignancy: ten years' experience at a cancer center and implications for management. Blood 90, 999-1008 (1997).

34 Hennequin, C. et al. Invasive Fusarium infections: a retrospective survey of 31 cases. The French Groupe d'Etudes des Mycoses Opportunistes. J. Med. Vet. Mycol. 35, 107-114 (1997).

35 Morrison, V. A., Haake, R. J. \& Weisdorf, D. J. The spectrum of non-Candida fungal infections following bone marrow transplantation. Medicine 72, 78-89 (1993).

36 Guarro, J. \& Gene, J. Fusarium infections. Criteria for the identification of the responsible species. Mycoses 35, 109-114 (1992).

37 Pfeffer, S., Hohne, W., Branner, S., Wilson, K. \& Betzel, C. X-Ray structure of the antibiotic bacitracin A. FEBS Lett. 285, 115-119 (1991).

38 National Committee for Clinical Laboratory Standards. Methods for Dilution Antimicrobial Susceptibility Tests for Bacteria that Grow Aerobically, 6th edn, Approved Standard M07-A6. (NCCLS, Villanova, PA, USA, 2003).

39 National Committee for Clinical Laboratory Standards. Reference Method for Broth Dilution Antifungal Susceptibility Testing of Filamentous Fungi. Approved standard. NCCLS document M38-A. (Clinical and Laboratory Standards Institute, Villanova, PA, 2002).

40 National Committee for Clinical Laboratory Standards. Development of In Vitro Susceptibility Testing Criteria and Quality Control Parameters. Approved guideline, 2nd edn. NCCLS document M23-A2 (Clinical and Laboratory Standards Institute, Villanova, PA, 2001)

41 National Committee for Clinical Laboratory Standards. Reference Method for Broth Dilution Antifungal Susceptibility Testing of Yeasts. Approved standard, 2nd edn. 
NCCLS document M27-A2 (Clinical and Laboratory Standards Institute, Villanova, PA, 2002).

42 Poitout, S. \& Bues, R. Elevage de plusieurs espèces de Lépidoptères Noctuidae sur milieu artificiel riche et sur milieu artificiel simplifié. Ann. Zool. Ecol. Anim. 2, 79-91 (1970).

43 Ahmad, I. M., Waldbauer, G. P. \& Friedman, S. A defined artificial diet for the larvae of Manduca sexta. Entomol. Exp. Appl. 53, 189-191 (1989).

44 Rowe, G. E. \& Welch, R. A. Assays of hemolytic toxins. Methods Enzymol. 235, 657-667 (1994).

45 Anggraeni, T. \& Ratcliffe, N. A. Studies on cell-cell cooperation during phagocytosis by purified haemocyte populations of the wax moth, Galleria mellonella. J. Insect. Physiol. 37, 453-460 (1991).

46 Rance, M. et al. Improved spectral resolution in cosy ${ }^{1} \mathrm{H}$ NMR spectra of proteins via double quantum filtering. Biochem. Biophys. Res. Commun. 117, 479-485 (1983).

47 Derome, A. E. \& Williamson, M. P. 2D homonuclear shift correlation phase sensitive using TPPI with double quantum filter phase cycle. J. Magn. Reson. 88, 177-185 (1990).
48 Bax, A. \& Davis, G. D. Practical aspects of two-dimensional treansverse NOE spectroscopy. J. Magn. Reson. 65, 355-360 (1985).

49 Rance, M. Improved techniques for homonuclear rotating-frame and isotropic mixing experiments. J. Magn. Reson. 74, 557-564 (1987).

50 Macura, S., Huang, Y., Sutter, D. \& Ernst, R. R. Two-dimensional chemical exchange and cross-relaxation spectroscopy of coupled nuclear spins. J. Magn. Reson. 43, 259-281 (1981).

51 Marion, D., Ikura, M., Tschudin, R. \& Bax, A. Rapid recording of 2D NMR-spectra without phase cycling-application to the study of hydrogen-exchange in proteins. J. Magn. Reson. 85, 393-399 (1989).

52 Bodenhausen, G. \& Ruben, D. J. Natural abundance nitrogen-15 NMR by enhanced heteronuclear spectroscopy. Chem. Phys. Lett. 69, 185-189 (1980).

$53 \mathrm{Bax}, \mathrm{A}$. \& Summers, M. F. ${ }^{1} \mathrm{H}$ and ${ }^{13} \mathrm{C}$ assignments from sensitivity-enhanced detection of heteronuclear multiple-bond connectivity by $2 \mathrm{D}$ multiple quantum NMR. J. Am. Chem. Soc. 108, 2093-2094 (1986).

54 Bax, A. \& Marion, D. Improved resolution and sensitivity in ${ }^{1} \mathrm{H}$-detected heteronuclear multiple-bond correlation spectroscopy. J. Magn. Reson. 78, 186-191 (1988).

55 Wüthrich, K. NMR of Proteins and Nucleic Acids (John Wiley \& Sons, New York, 1986). 